\title{
Effect of stress ratio and specimen thickness on fatigue crack growth of CK45 steel
}

\author{
J.D.M. Costa * J.A.M. Ferreira \\ Department of Mechanical Engineering, University of Coimbra, DEMIFCTUC, Pinhal de Marrocos, 3030 Coimbra, Portugal
}

\begin{abstract}
Presented are the effect of stress ratio and thickness on the fatigue crack growth rate of CK45 steel according to DIN 17200. Test results are obtained for constant amplitude load in tension with three stress ratios of $R=0,0.2$ and 0.4 and three specimen thicknesses of $B=6,12$ and $24 \mathrm{~mm}$. Microgauge crack opening values were used to calculate $\Delta K_{\text {eff }}$ values from which the $\mathrm{d} a / \mathrm{d} N-\Delta K_{\text {eff }}$ curves are obtained. Crack closure can be applied to explain the influence of mean stress and specimen thickness on the fatigue crack growth rate in the second regime of the two-parameter crack growth rate relation. An empirical model is chosen for calculating the normalized load ratio parameter $U$ as a function of $R, B$ and $\Delta K$ and, for correlating the test data. (c) 1998 Elsevier Science Ltd. All rights reserved.
\end{abstract}

\section{Introduction}

Crack closure has played a central role in the study of fatigue crack propagation [1]. A large number of researchers have made attempts to understand the influences of mean stress [2,3] and specimen thickness $[4,5]$ on the fatigue crack growth rate based on the crack closure argument. These influences, however, were not always attributed to the crack closure phenomenon [6]. The reasons for such misdirected implications are partly due to the lack of measurement accuracy and/or improper experimental techniques when determining the crack closure.

Cause of crack closure [7] has been attributed to plasticity, oxidation and surface roughness. Except for high stress ratios or high $\Delta K$ values, fatigue crack growth can be affected by crack closure due

\footnotetext{
${ }^{*}$ Corresponding author. Tel.: +351 39790 700; fax: +351 39 790 701; e-mail: jose.domingos@mail.dem.uc.pt.
}

to plasticity in the two-parameter crack growth rate relation, Regime II and by oxidation and surface roughness in Regime I of the two-parameter crack growth rate relation. The influence of mean stress on the fatigue crack growth rate in the former case has been explained by crack closure using the normalized load ratio parameter $U$ as a function of $R$ alone [3,8]; of $R$ and $K_{\max }$ [9]; and of $R$ and $\Delta K[10]$. Sometimes, $U$ tends to increase with $R$ and decrease with increasing $K_{\max }$ [11,12]. This, however, is in contrast with the conclusion in Ref. [9] that $U$ increases with $K_{\max }$.

Two different specimen thicknesses $B=0.3$ and $6.35 \mathrm{~mm}$ were used to study the crack growth rate [13] for two different steels (1018 and 9CK-1Mo) and three aluminium alloys (2024, 6061 and IN9021). Specimen thickness influence on the crack rate growth were not present for the 1018 steel and 2024 and 6061 aluminium alloys. Thickness effects observed for the $9 \mathrm{Cr}-1 \mathrm{Mo}$ and IN9021 alloys were attributed to the pronounced contraction at the lateral surfaces near the crack 
tip. A reduction in $\Delta K_{\text {eff }}$ thus prevails. Surface contractions for these two materials were obtained. Specimen thickness variation had little influence on $U$. But for values below certain critical thickness $B_{\mathrm{c}}$, the $U$ parameter was very sensitive to thickness variations.

Three different thicknesses of compact tension specimens were tested in fatigue for three stress ratios values. The objectives of this work are to measure the crack length and crack closure for fatigue; to analyze the crack closure variation with $K_{\max }$, (or $\Delta K$ ), for different $R$ and $B$ values; to obtain the $\mathrm{d} a / \mathrm{d} N-\Delta K_{\text {eff }}$ curves such that the influences of $B$ and $R$ could be eliminated; and to propose an empirical model that could correlate $U$ with $R, B$ and $\Delta K$.

\section{Experimental considerations}

Chemical composition and the mechanical properties of CK45 (DIN 17200) steel, are shown in Tables 1 and 2, respectively.

Fatigue tests were conducted for the compact tension (CT) specimens with three different thicknesses: $B=6,12$ and $24 \mathrm{~mm}$ according to the ASTM E647 standard [14]. The specimens were obtained in the transverse longitudinal direction from a laminated bar with rectangular section $30 \times 60 \mathrm{~mm}^{2}$. The tests were performed in a loadcontrolled servohydraulic INSTRON (model 1341) machine with $100 \mathrm{KN}$ of capacity. The load is constant amplitude with a frequency of $20 \mathrm{~Hz}$. Optical and direct current potential drop were used to measure the crack length. The specimens were machined and polished mechanically.

Table 1

Chemical composition of CK45 (DIN 17200) steel

\begin{tabular}{lllll}
\hline $\mathrm{C}(\%)$ & $\mathrm{Si}(\%)$ & $\mathrm{Mn}(\%)$ & $\mathrm{P}(\%)$ & $\mathrm{S}(\%)$ \\
\hline $0.42-0.50$ & $0.15-0.35$ & $0.50-0.80$ & 0.035 & 0.35 \\
\hline
\end{tabular}

Table 2

Mechanical properties of CK45 (DIN 17200) steel

\begin{tabular}{llll}
\hline$\sigma_{\mathrm{r}}(\mathrm{MPa})$ & $\sigma_{\mathrm{c}}(\mathrm{MPa})$ & $\varepsilon_{\mathrm{r}}(\%)$ & Hardness HB \\
\hline $670-820$ & 420 & $>16$ & 205 \\
\hline
\end{tabular}

The optical measurements were made in travelling microscope (30X) with an accuracy of 10 $\mu \mathrm{m}$. The direct current potential drop (DCPD) method consists of a power supply KEPCO, (model A-TE6-50) (with 0-50 A) and a microvoltimeter RACAL DANA (model 5001) with 1 $\mu \mathrm{V}$ of resolution. During the tests, the current was constant in the range 30-50 A. Note that $30 \mathrm{~A}$ were used for thickness $B=6 \mathrm{~mm}$, and $50 \mathrm{~A}$ for $B=24 \mathrm{~mm}$. The measurements of the DCPD were in the range $150-2000 \mu \mathrm{V}$ from the start until the end of the test. The cables that conducted the current to the specimens were connected by using two treaded bolts at the top and bottom surfaces of the specimens. The DCPD was obtained by two electrical conductors of nickel with $0.1 \mathrm{~mm}$ of diameter welded by the resistance welding process. The machine used to perform the welds was a Shandon model Elliot.

Crack closure measurements (opening loads) were made using a Elber type gauge [1] near the crack tip located above and below the crack surfaces where two holes of $0.5 \mathrm{~mm}$ diameter were drilled for the gauge pins. The distance between these points was $1.2 \mathrm{~mm}$ and about $1 \mathrm{~mm}$ from the crack tip. The load-displacement records were obtained at a frequency of $0.2 \mathrm{~Hz}$.

At the start of this series of tests, other types of crack closure measurement techniques were attempted namely, the Crack Mouth Gauge and the DCPD technique. In both cases, the results indicated that these transducers are not adequate due to insufficient sensibility. In the case of the DCPD technique, the load-displacement records did not correlate with the crack closure phenomenon.

From the load-displacement records, variations of the opening load $P_{\text {op }}$ were derived using the point where the curve begins to be linear during the loading part of the cycle as shown in Fig. 1. The parameters $U, K_{\text {op }}$ and $\Delta K_{\text {eff }}$ are given by the expressions:

$$
\begin{aligned}
& U=\left(P_{\max }-P_{\mathrm{op}}\right) /\left(P_{\max }-P_{\min }\right), \\
& K_{\mathrm{op}}=K_{\max }-U \Delta K, \\
& \Delta K_{\mathrm{eff}}=U \Delta K
\end{aligned}
$$




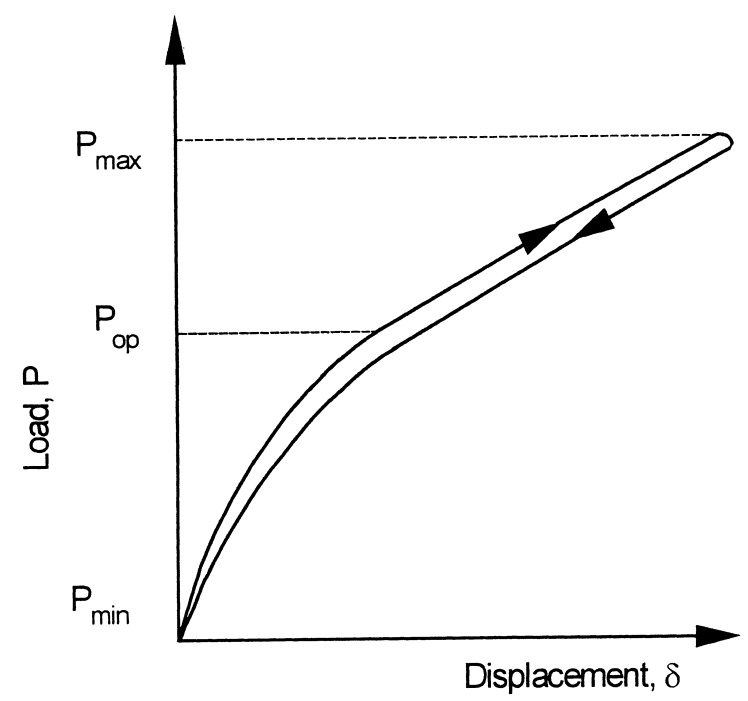

Fig. 1. Schematic presentation for the determination of the opening load, $P_{\text {op }}$.

\section{Results and discussions}

Table 3 shows some $U$ expressions for past models. Most of them consider $U$ as a function of $R$ only. Other models treat $U$ as function of $R$ and $\Delta K$ or $K_{\max }$. However, none of them include the influence of specimen thickness.

\subsection{Mean stress and specimen thickness}

The influence of stress ratio on fatigue crack growth can be seen from Fig. 2(a) for $B=6 \mathrm{~mm}$ and $R=0,0.2$ and 0.4 . Strong influence of the stress ratio on fatigue crack growth rate is observed. As $\Delta K$ increases, the influence of $R$ on $\mathrm{d} a / \mathrm{d} N$ decreases. The crack growth rate $\mathrm{d} a / \mathrm{d} N$ increases with $R$; this trend is more pronounced between $R=0$ and 0.2 than that between $R=0.2$ and 0.4 . For high values of $\mathrm{d} a / \mathrm{d} N$ near $10^{-3} \mathrm{~mm} /$ cycle, the influence of $R$ is nearly absent between $R=0.2$ and 0.4 .

Figs. 2(b) and 2(c) show the $\mathrm{d} a / \mathrm{d} N-\Delta K$ plots for $B=12$ and $24 \mathrm{~mm}$, respectively. For $B=12$ $\mathrm{mm}$, Fig. 2(b) shows that the same behavior is observed for $B=6$ and $12 \mathrm{~mm}$. However, the influence of $R$ on $\mathrm{d} a / \mathrm{d} N$ is less pronounced, and becomes virtually absent for $\mathrm{d} a / \mathrm{d} N$ close to $10^{-3}$ $\mathrm{mm} /$ cycle and still $\Delta K=50 \mathrm{MPa} \mathrm{m}^{-1 / 2}$.

While the mean stress effect for $B=24 \mathrm{~mm}$ can be observed in Fig. 2(c), it is not as significant as than for $B=6$ and $12 \mathrm{~mm}$.

Fig. 3(a) shows the influence of specimen thickness on crack growth for $R=0$. It can be seen that $\mathrm{d} a / \mathrm{d} N$ increases with thickness. This effect becomes less significant as $\Delta K$ increases; it is more pronounced between $B=6$ and $12 \mathrm{~mm}$ than between $B=12$ and $24 \mathrm{~mm}$.

The plots of $\mathrm{d} a / \mathrm{d} N-\Delta K$ obtained for the other stress ratios $R=0.2$ and 0.4 show similar trends but with less influence of $B$ on $\mathrm{d} a / \mathrm{d} N$.

\subsection{Opening load stress intensity factor}

Since fatigue crack growth rate has shown a strong dependence on both stress ratio and specimen thickness, a crack closure analysis was carried out to correlate the results with $\Delta K_{\text {eff }}$ initially proposed in Ref. [3]. A typical plot of the crack

Table 3

Models to estimate $U$

\begin{tabular}{lll}
\hline Material & Reference & Model \\
\hline $2024-\mathrm{T} 3 \mathrm{Al}$ & {$[3]$} & $U=0.5+0.4 R, \quad 0.1<R<0.7$ \\
$2024-\mathrm{T} 3 \mathrm{Al}$ & {$[8]$} & $U=0.55+0.35 R+0.1 R^{2}, \alpha=0.1$ \\
Titanium & {$[9]$} & $U=\frac{1}{1-R}\left[1-\frac{6.67 R-4.27}{K_{\max }}\right]$ \\
$6063-\mathrm{T} 6 \mathrm{Al}$ & {$[10]$} & $U=\left(\frac{13.5 R+5.925}{1000}\right) \Delta K+1.35 R+0.223$ \\
Mild steel & {$[15]$} & $U=0.7+0.15 R(2+R)$ \\
Steel & {$[16]$} & $U=0.75+0.25 R$ \\
\hline
\end{tabular}




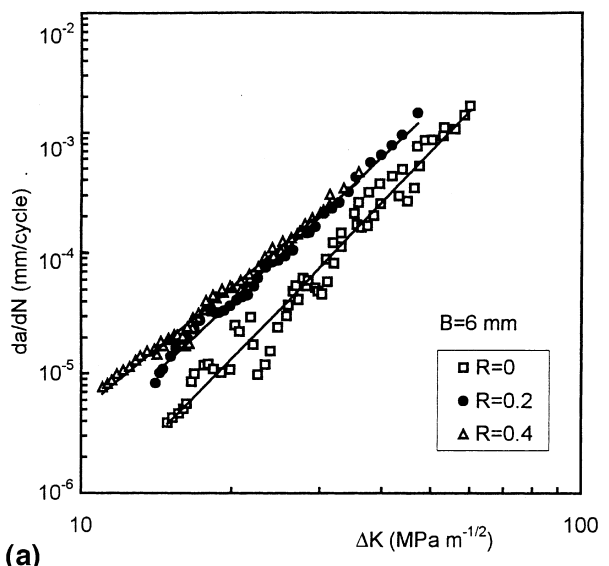

(a)

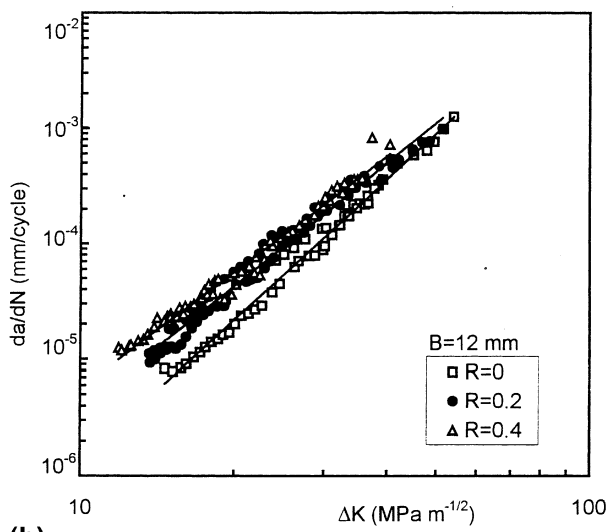

(b)

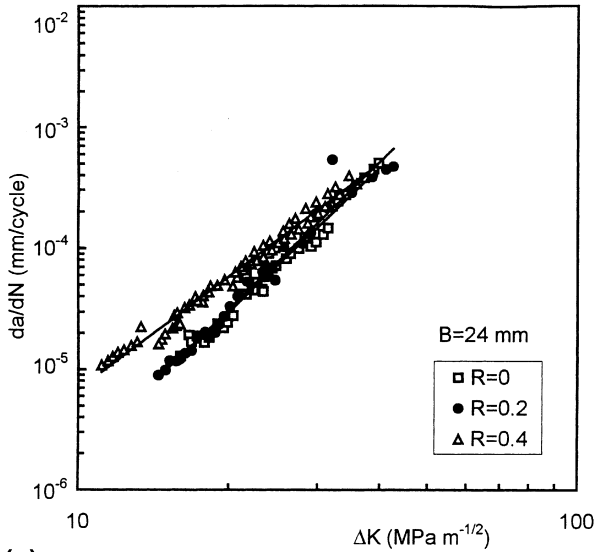

(c)

Fig. 2. $\mathrm{d} a / \mathrm{d} N$ versus $\Delta K$ curves for $R=0,0.2$ and 0.4 : (a) $B=6$ mm; (b) $B=12 \mathrm{~mm}$; (c) $B=24 \mathrm{~mm}$.

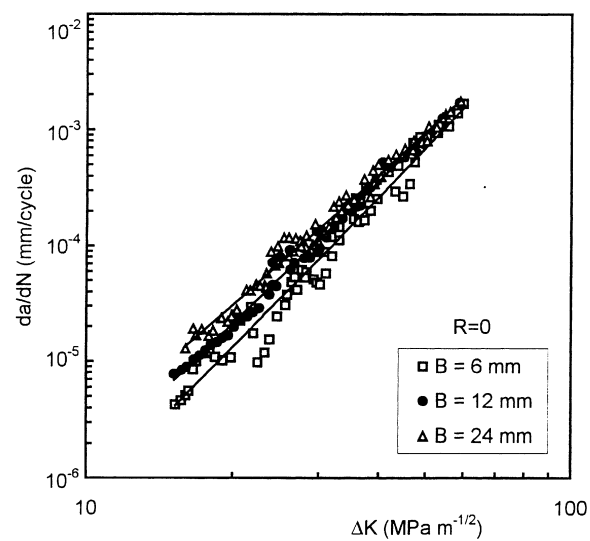

(a)

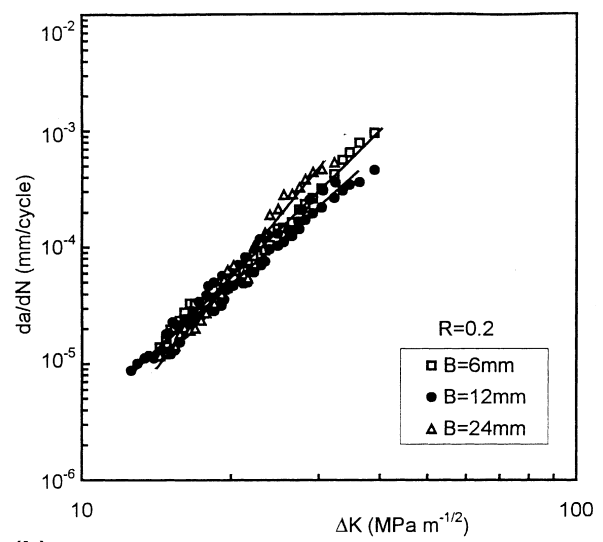

(b)

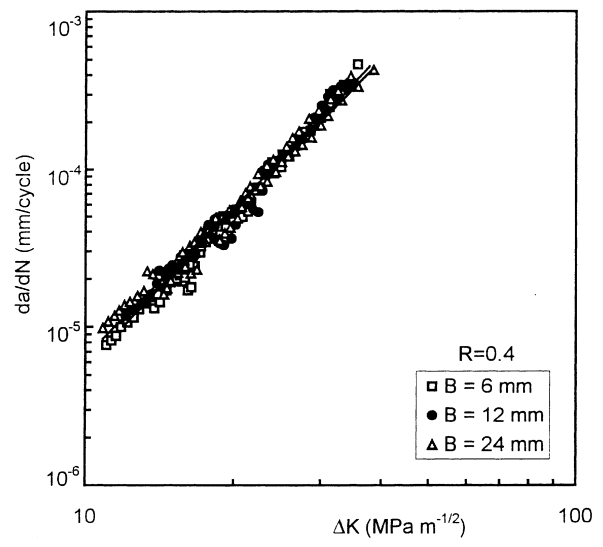

(c)

Fig. 3. $\mathrm{d} a / \mathrm{d} N$ versus $\Delta K$ curves for $B=6,12$ and $24 \mathrm{~mm}$ : (a) $R=0$; (b) $R=0.2$; (c) $R=0.4$. 


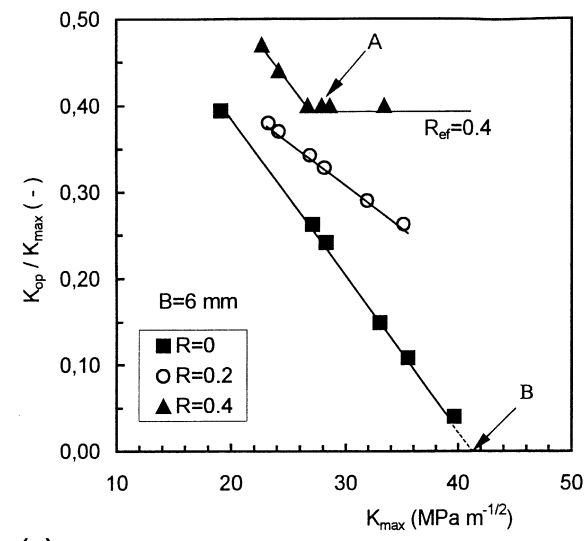

(a)

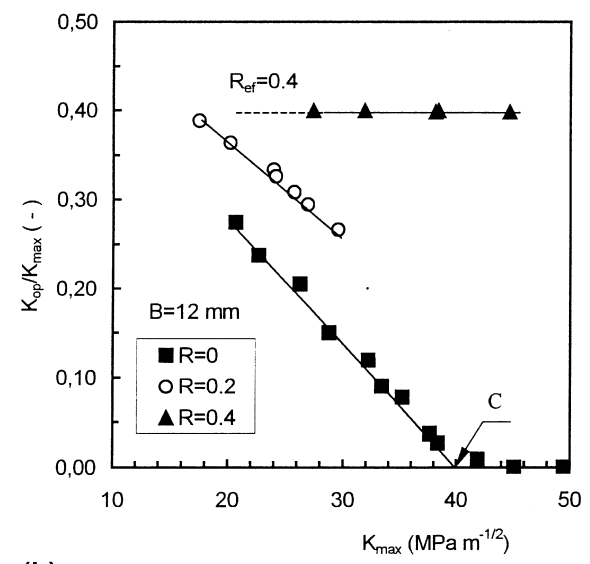

(b)

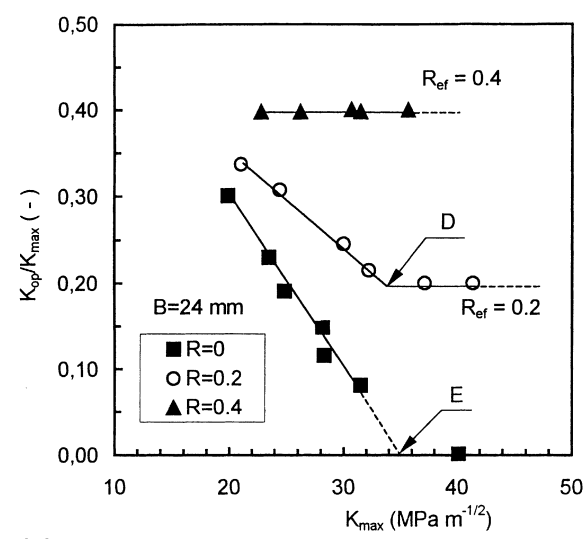

(c)

Fig. 4. $K_{\text {op }} / K_{\max }$ versus $K_{\max }$, for $R=0,0.2$ and 0.4 : (a) $B=6$ $\mathrm{mm}$; (b) $B=12 \mathrm{~mm}$; (c) $B=24 \mathrm{~mm}$. opening load obtained with the clip gauge was shown in Fig. 1, where $P_{\text {op }}$ is the opening load.

Fig. 4(a)-(c) present the variations of $K_{\mathrm{op}} / K_{\max }$ with $K_{\max }$ for $B=6,12$ and $24 \mathrm{~mm}$, respectively. All these plots are compared with the three values of the stress ratios $R=0,0.2$, and 0.4 . The points indicated in Figs. 4 and 5 represent values of $K_{\max }$ above which $K_{\mathrm{op}} / K_{\max }=R$. Numerical results are given in Table 4. Fig. 4(a) (for $B=6 \mathrm{~mm}$ ) shows that $K_{\mathrm{op}} / K_{\max }$ decreases as $K_{\max }$ increases until the minimum value $K_{\mathrm{op}} / K_{\min }$ was attained, where $R_{\text {eff }}=R$. For example at point $A$, where $K_{\max }=28$ $\mathrm{MPa} \mathrm{m}{ }^{-1 / 2}, K_{\mathrm{op}}<K_{\mathrm{min}}$, and $R_{\mathrm{eff}}=R=0.4$. For $R=0.2$, the condition $R_{\text {eff }}=R$ can be obtained only for $K_{\max } \approx 40 \mathrm{MPa} \mathrm{m}^{-1 / 2}$. From the trend of the curve for $R=0, R_{\text {eff }}=R$ is estimated to occur at point $B$ for $K_{\max } \approx 40 \mathrm{MPa} \mathrm{m}^{-1 / 2}$.

Fig. 4(b) shows that for $B=12 \mathrm{~mm}$ and $R=0.4$, crack closure measurements could not be obtained even for the lower values of $K_{\max }$. However, for $R=0.2, \quad K_{\text {op }} / K_{\max }$ decreases as $K_{\max }$ increases. Points $C$ corresponds to $K_{\max }=40 \mathrm{MPa} \mathrm{m}^{-1 / 2}$, above which the ratio $K_{\text {op }} / K_{\max }$ becomes constant and equals to $R=0$.

The results in Fig. 4(c) for $B=24 \mathrm{~mm}$ are similar to those for other thicknesses. Crack closure was not observed for $R=0.4$. For the others stress ratios, $K_{\text {op }} / K_{\max }$ tends to a lower limit defined by the stress ratio $R$, after which $K_{\mathrm{op}} / K_{\max }$ remains constant. Such a behavior is shown for $R=0.2$ for point $D$ at $K_{\max }=34 \mathrm{MPa} \mathrm{m}^{-1 / 2}$ and $R=0$ for point $E$ at $K_{\max }=36 \mathrm{MPa} \mathrm{m}^{-1 / 2}$

From the results plotted in Fig. 4(a)-(c), it can be concluded that:

- for $R=0.4$, the values of $K_{\text {op }}$ are higher than $K_{\min }$ only for lower thickness of $B=6 \mathrm{~mm}$ and for $K_{\max }<28 \mathrm{MPa} \mathrm{m}{ }^{-1 / 2}$. No crack closure was observed for the other thicknesses $B=12$ and $24 \mathrm{~mm}$, and therefore $R_{\text {eff }}=R$ in the range of $K_{\max }$ values was analyzed;

- for $R=0$ and $0.2, K_{\text {op }} / K_{\max }$ decreases as $K_{\max }$ increases until the minimum value was attained where $R_{\text {eff }}=R$;

- the ratio $K_{\mathrm{op}} / K_{\max }$ is lower for the lower stress ratios;

- the condition $K_{\mathrm{op}} / K_{\mathrm{max}}=1$ was attained for $K_{\max }$ values that increases as $R$ decreases, since $R$ is positive. 


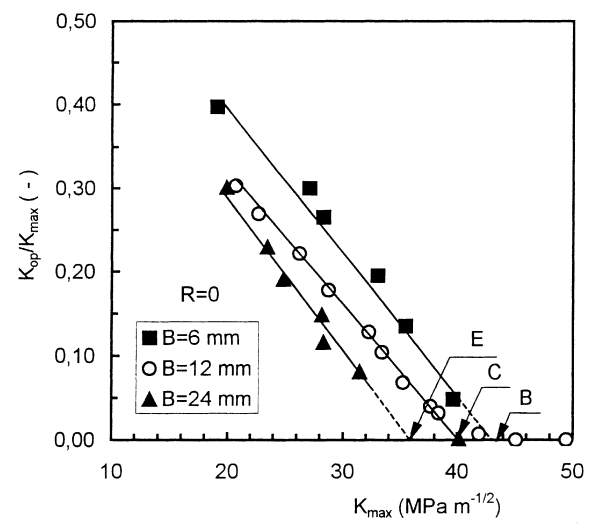

(a)

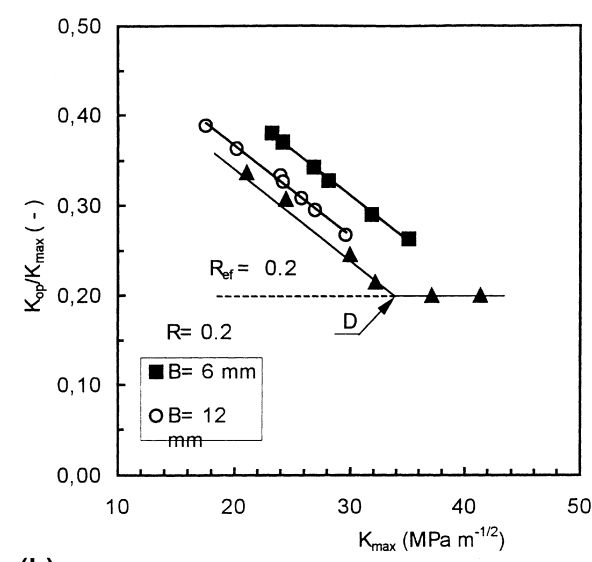

(b)

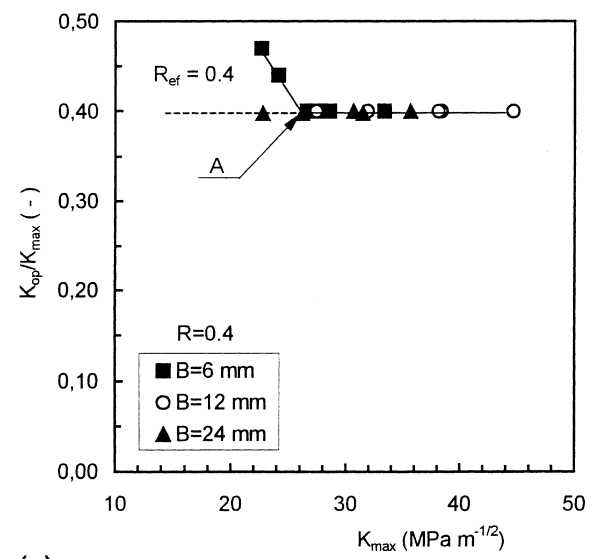

(c)

Fig. 5. $K_{\mathrm{op}} / K_{\max }$ versus $K_{\max }$, for $B=6,12$ and $24 \mathrm{~mm}$ : (a) $R=0$; (b) $R=0.2$; (c) $R=0.4$.
Table 4

Key points on the curves $K_{\mathrm{op}} / K_{\max }-K_{\max }$ above which $K_{\mathrm{op}} /$ $K_{\max }=R$

\begin{tabular}{llrll}
\hline Point & $R$ & \multicolumn{1}{c}{$B$} & $\Delta K\left(\mathrm{MPa} \mathrm{m}^{-1 / 2}\right)$ & $K_{\max }\left(\mathrm{MPa} \mathrm{m}^{-1 / 2}\right)$ \\
\hline$A$ & 0.4 & 6 & 16.8 & 28 \\
$B$ & 0 & 6 & 42 & 42 \\
$C$ & 0 & 12 & 40 & 40 \\
$D$ & 0.2 & 24 & 27.2 & 34 \\
$E$ & 0 & 24 & 36 & 36 \\
\hline
\end{tabular}

Plotted in Fig. 5(a)-(c) are, respectively, the results of $K_{\mathrm{op}} / K_{\max }$ against $K_{\max }$ for different stress ratio of $R=0,0.2$ and 0.4 . Three different specimen thicknesses of $B=6,12$ and $24 \mathrm{~mm}$ are covered. The behavior observed for $R=0$ and 0.2 in Fig. 5(a) and (b) is similar. The influence of specimen thickness on crack represented by $K_{\mathrm{op}} / K_{\max }$ is highest for $B=6 \mathrm{~mm}$. In Fig. 5(a), point $E$ corresponds, to $K_{\max }=36 \mathrm{MPa} \mathrm{m}^{-1 / 2}$ (for $B=24 \mathrm{~mm}$ ) above which $R_{\text {eff }}=0$. Point $C$ corresponds to $K_{\max }=40 \mathrm{MPa} \mathrm{m}^{-1 / 2}$ (for $B=24 \mathrm{~mm}$ ) above which $R_{\text {eff }}=0$. The curves in Fig. 5(c) pertain to $R=0.4$. Crack closure is observed only for $B=6 \mathrm{~mm}$ and $K_{\max }$ below $28 \mathrm{MPa} \mathrm{m}^{-1 / 2}$. For $B=12$ and $24 \mathrm{~mm}$, the values of $K_{\text {op }}$ are below $K_{\min }$. Therefore, for $K_{\max }>28 \mathrm{MPa} \mathrm{m} \mathrm{m}^{-1 / 2}$ there is no influence of specimen on crack closure for this stress ratio.

\subsection{Normalized load ratio parameter}

Other forms of crack closure data can be represented by plotting the normalized load ratio parameter $U$ defined by Eq. (1) as a function of $\Delta K$. Fig. 6 shows that $U$ tends to increase with $\Delta K$ for $B=6 \mathrm{~mm}$ and all values of $R$. For $\Delta K>16$ MPa $\mathrm{m}^{-1 / 2}$ and $R=0.4, U$ takes a constant value of unity. Curves for $B=12$ and $24 \mathrm{~mm}$ are not shown; their trends are similar to those in Fig. 6 except that the effect of $R$ is less pronounced.

Displayed in Fig. 7 are variations of $U$ versus $\Delta K$ for $R=0$. For a given $\Delta K, U$ increases with the specimen thickness. Note that points $E$ and $C$ correspond to $U=1$ for $B=24 \mathrm{~mm}(\Delta K=36 \mathrm{MPa}$ $\left.\mathrm{m}^{-1 / 2}\right)$ and $B=12 \mathrm{~mm}\left(\Delta K=40 \mathrm{MPa} \mathrm{m}^{-1 / 2}\right)$, respectively. The data for $R=0.2$ and $0.4 \mathrm{~mm}$ are similar but not shown. 


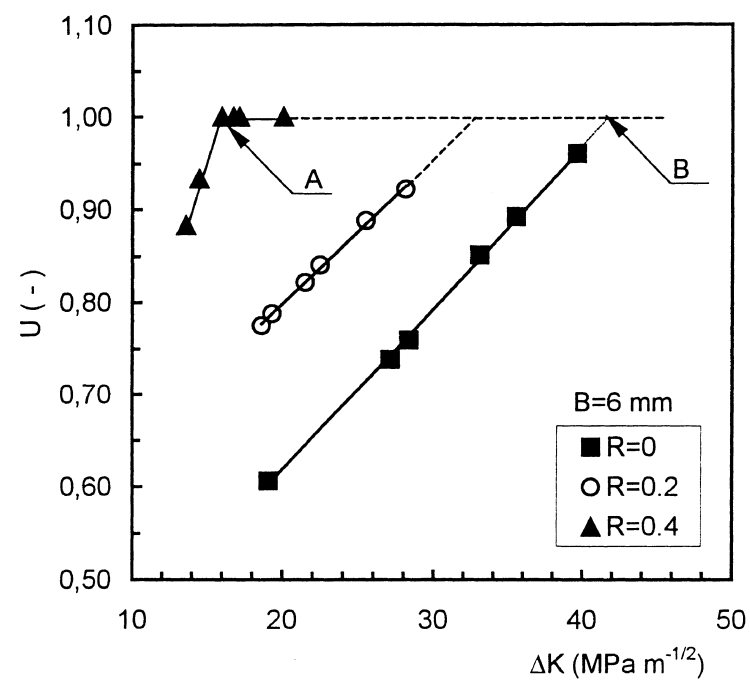

Fig. 6. $U$ versus $\Delta K, B=6 \mathrm{~mm}, R=0,0.2$ and 0.4 .

\subsection{Effective stress intensity factor}

The change of effective stress intensity factor $\Delta K_{\text {eff }}$ can be calculated from $U$ and $\Delta K$ according to Eq. (3). The objective is to represent the crack closure data by a single curve independent of $R$ or $B$.

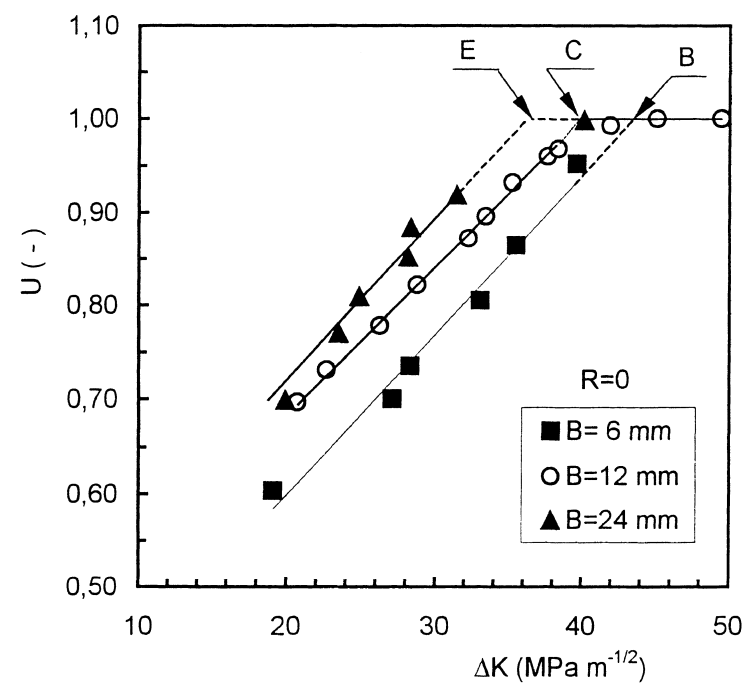

Fig. 7. $U$ versus $\Delta K, R=0, B=6,12$ and $24 \mathrm{~mm}$.
From the values of $U$ calculated, the curves $\mathrm{d} a$ l $\mathrm{d} N-\Delta K_{\text {eff }}$ were derived. The objective is to analyze if the crack closure by itself reduces all the $\mathrm{d} a$ l $\mathrm{d} N-\Delta K$ curves at a unique curve of $\mathrm{d} a$ l $\mathrm{d} N-\Delta K_{\text {eff }}$ independent $R$ or $B$.

Fig. 8 shows these results for the three stress ratios and thicknesses. All results tend to fall within a width for all values of $R$ or $B$ when $\mathrm{d} a / \mathrm{d} N$ is plotted against $\Delta K_{\text {eff }}$ according to

$\mathrm{d} a / \mathrm{d} N=2 \times 10^{-8} \Delta K_{\text {eff }}^{2.7468}$.

The correlation factor is 0.98 .

The models of $U$ shown in Table 3 present this parameter as a function of $R$ only or of $R$ and $\Delta K$ or $K_{\max }$. However, this work showed that the thickness can also have an important effect on crack closure. Presented in Eq. (5) is an expression that relates $U$ to $R, \Delta K$ and $B$ by using a multiple linear regression:

$$
\begin{array}{cl}
U=0.716 R+0.012 \Delta K+0.144(\mathrm{~B} / \mathrm{W}) \\
+0.433 & \text { if } \quad \beta<0.567 \\
U=1 & \text { if } \quad \beta>0.567
\end{array}
$$

where

$\beta=0.716 R+0.0121 \Delta K+0.144(\mathrm{~B} / \mathrm{W})$.

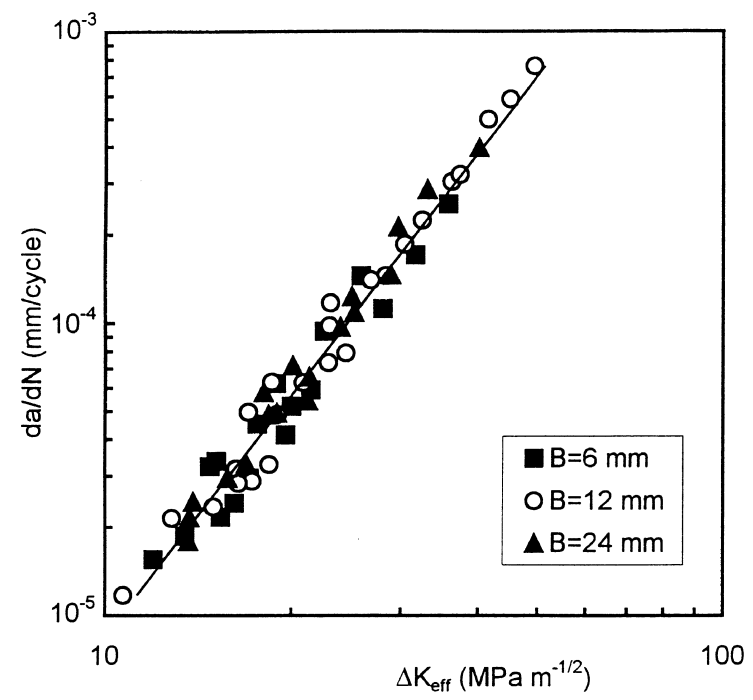

Fig. 8. $\mathrm{d} a / \mathrm{d} N$ versus $\Delta K_{\text {eff }}$, for $R=0,0.2$ and 0.4 and $B=6,12$ and $24 \mathrm{~mm}$. 
Although the correlation factor 0.941 is low, this equation can be used for the determination of $U$ in for CK steel in the range for $0<R<0.4$ and $6<B<24 \mathrm{~mm}$.

The validation of this equation was analyzed by plotting $\mathrm{d} a / \mathrm{d} N$ as a function of the values of $\Delta K_{\text {eff }}$. Fig. 9 shows these results for the three stress ratios and thicknesses. A continuous band is obtained that appears to be appropriate for determining the influence of $R$ and $B$ on $U$.

Proposed in Ref. [3] using $U$ from Eq. (5), it can be stated that

$\mathrm{d} a / \mathrm{d} N=9 \times 10^{-9} \Delta K_{\text {eff }}^{2.95}$.

The difference of the values of $C$ and $m$ constants between Eqs. (4) and (7) are due to the use of $\mathrm{d} a / \mathrm{d} N-\Delta K$ data calculated from Eq. (5) for obtaining Eq. (7), while Eq. (4) is found from the experimental data for $\mathrm{d} a / \mathrm{d} N$ and $\Delta K$.

\section{Conclusions}

1. A strong influence of both stress ratio $R$ and specimen thickness $B$ on the fatigue crack growth was observed for the CK45 steel. $\mathrm{d} a / \mathrm{d} N$ increases with $R$ or $B$. The influence of specimen thickness is more pronounced for the lower stress ratio $R=0$. The influence of $R$ and $B$ on $\mathrm{d} a / \mathrm{d} N$ tends to de-



Fig. 9. $\mathrm{d} a / \mathrm{d} N$ versus $\Delta K_{\text {eff }}$, using the model of $U$ (Eq. (5)). $R=0,0.2$ and 0.4 , and $B=6,12$ and $24 \mathrm{~mm}$. crease as $\Delta K$ increases while $\mathrm{d} a / \mathrm{d} N$ is more sensitive to change of $R$ for the lower thickness range.

2. Crack closure data were obtained and plotted for $R_{\mathrm{eff}}=K_{\mathrm{op}} / K_{\max }$ versus $K_{\max }$. As $K_{\max }$ increases $R_{\text {eff }}$ decreases until the $R_{\text {eff }}=R$ condition was attained. $K_{\mathrm{op}} / K_{\max }$ decreases with $R$. No crack closure was observed for $R=0.4$ except for the lowest specimen thickness $B=6 \mathrm{~mm}$. For constant stress ratio $R, R_{\text {eff }}$ increases as the specimen thickness decreases.

3. The crack closure load parameter $U$ was also determined and plotted versus $\Delta K$. It increases with $R$ and $B$. The influence of $R$ on $U$ is more strong for the lowest thickness $B=6 \mathrm{~mm}$. Also, the influence of $B$ on $U$ is stronger for $R=0$ than for $R=0.2$ and is virtually insignificant for $R=0.4$.

4. Despite some scatter obtained for the curves $\mathrm{d} a / \mathrm{d} N-\Delta K_{\text {eff }}$ the results for the three stress ratios and thicknesses are represented by a single curve for the two-parameter crack growth rate relation as applied to the CK45 steel.

5. A model of $U$ as function $R, B$ and $\Delta K$ was proposed based on the experimental crack closure data. This model is limited to $0<R<0.4$ and $6<B<24 \mathrm{~mm}$.

\section{References}

[1] W. Elber, Fatigue crack closure under cyclic tension, Eng. Fract. Mech. 2 (1970) 37-45.

[2] A.F. Blom, D.K. Holm, An experimental and numerical study of crack closure, Eng. Fract. Mech. 22 (1984) 9971011.

[3] W. Elber, The significance of fatigue crack closure, ASTM STP415 (1971) 230-242.

[4] J. Schijve, Tour lectures on fatigue crack growth, Eng. Fract. Mech. 11 (1979) 167-221.

[5] O.N. Romaniv, A.N. Track, Y.N. Lenets, Effects of fatigue crack closure on near threshold crack resistance on structural steels, Fat. Fract. Eng. Mat. Struct. 10 (1987) 263-272.

[6] N.C. Lafarie-Frenot, J. Petit, C. Gasc, A contribution to the study of fatigue crack closure in vacuum, Fat. Eng. Mat. 1 (1979) 431-438.

[7] R.O. Ritchie, Slow crack growth macroscopic aspects, in: R.B. Tait, G.G. Garret (Eds.), Proceedings of the 2nd National Conference on Fracture, University of Witwatersrand, Johannesburg, Pergamon Press, Oxford, 1984. 
[8] J. Schijve, Some formulas for crack opening stress level, Eng. Fract. Mech. 14 (1981) 461-465.

[9] V. Bachmann, D. Munz, Crack closure in fatigue of titanium alloy, Int. J. Fract. 11 (1975) 713-716.

[10] Y.P. Srivastava, S.B.L. Garg, Influence of R on effective stress range ratio and crack growth, Eng. Fract. Mech. 22 (1985) 915-926.

[11] K.D. Unangst, T.T. Shih, R.P. Wei, Crack closure in 2219T851 Al-alloy, Eng. Fract. Mech. 9 (1977) 725-734.

[12] N.J.I. Adains, Fatigue crack closure at positive stresses, Eng. Fract. Mech. 4 (1972) 543-554.

[13] H. Bao, A.J. McEvely, The effect of thickness on the rate of fatigue crack growth, in: G. Lutjering, Nowack (Eds.),
Proceedings of the 6th International Fatigue Congress, Berlin, Germany, Pergamon Press, Oxford, 1996, pp. 381386.

[14] Standard test method for constant-load-amplitude fatigue crack growth rates above 10-8 m/cycle, ASTM E 647-86 (1987) 765-783.

[15] R. Kumar, K. Singh, Influence of stress ratio on fatigue crack growth in mild steel, Eng. Fract. Mech. 50 (1995) 377-384.

[16] S.J. Madox, T.R. Curney, A.M. Mummey, G.S. Booth, An investigation of the influence of applied stress ratio on fatigue crack propagation in structural steels, Research Report 72/1978, Welding Institute, 1978. 